\title{
An Extensive Review on the Effects of Deep Cryogenic Treatment on Cutting Tools
}

\author{
Manjunath $S^{*}, 1$ and Ajay Kumar B $S^{2}$ \\ ${ }^{1}$ Dept. of Mechanical Engineering, Jain University, Bengaluru, India \\ ${ }^{2}$ Dept. of Mechanical Engineering, Bangalore Institute of Technology, Bengaluru, India.
}

Received 22 January 2016; Accepted 2 July 2016

\begin{abstract}
The cutting tool life assessment is a one of the important factor in reducing the machining cost. High-speed steel (HSS) devices are the most normally utilized instruments as a part of little and medium-scale industry. These slicing apparatuses are subjected to procedures, for example, heat treatment with a specific end goal to enhance their execution. Cryogenic treatment, which is otherwise called below zero warmth treatment, has made huge commitments to the change of wear resistance, apparatus life, dimensional trustworthiness, and item nature of cutting instruments. Hence, the present review discovers the previous studies those are conducted on titanium, stainless steel, and wear resistant specifically focusing on deep cryogenic treatment. Further, the review also briefly introduces the concept of deep cryogenic and its cooling system. Finally, the review would conclude with the gaps prevailing in the previous studies and provide recommendations for future studies.
\end{abstract}

Keywords Cryogenic treatment; Deep Cryogenic treatment, face milling, wear resistant, cutting tools.

\section{Introduction}

The utilization of warm medications to enhance mechanical properties of metal parts is an old craftsmanship extended down the ages until today. Huge numbers of the created forms apply medicines in a scope of temperature higher than room temperature. The primary endeavors to perform subzero medicines were examined toward the start of the twentieth century, however the real enthusiasm on cryogenic treatment (or cryotreatment, CT) was produced during the last years of the century [1]. The "cryogenic" word is created from the Greek word "krys" which means cold. Heat treatment applied at unconventionally low temperatures is referred to as cryogenic [2]. This treatment has been given different names in different sources such as cryo, deep cryogenic treatment, cryogenics, cryo processing are some of the sources. Cryogenic treatment started to be utilized as a part of the late sixteenth century to upgrade the mechanical properties of materials.

The essential CT comprises in a continuous cooling of the segment until the characterized temperature, holding it for a given time (solidifying time) and afterward logically driving it back to the room temperature. The point is to acquire a change of mechanical properties, ordinarily hardness and wear resistance, yet in late tests exhaustion

\footnotetext{
*E-mail address: manjunaths843@gmail.com

ISSN: 1791-2377 (c) 2016 Eastern Macedonia and Thrace Institute of Technology.All rights reserved.
}

confine as well, and to accomplish an ideal proportion between clashing properties, similar to hardness and strength. Generally, the concept of cryogenics denotes the science that deals with very low temperatures. On the other hand, this has not been especially determined and could be demonstrated to the temperatures lesser than $120 \mathrm{~K}$ which is the air's breaking point [3] or is $100 \mathrm{~K}$ [4]. Ordinarily average cryogens which is in the method of fluid gasses and could be called as fluid nitrogen (LN2), helium (LHe), oxygen, ethane, methane and argon. Yet, in machining, at times temperatures more than $100 \mathrm{~K}$ would also bestated by some authors as cryogenics, for instance, cryogenic machining that uses solid carbon dioxide and/or liquid $[5,6$, 7] and even chilled air at very low temperatures $[8,9]$.

In reality, there are major differences between the different cycles and treatments performed at different temperatures. Consider the case of the treatments performed at $-84{ }^{\circ} \mathrm{C}$ and at $-196{ }^{\circ} \mathrm{C}$. The improvement in wear resistance is less in the former than the later. Whatever may be the scope of treatment, the purpose remains the same, i. e. to increase the hardness of surface, wear resistance, and toughness of the cutting tool. It has been reported that cryogenic treatment assists in increasing the wear resistance of steels while its implementation through cutting tools. This being the reason; numerous studies have been conducted to evaluate the resistance power and its longevity of cutting tools treated with cryogenic materials. For example, in [10] where they analyzed the change in wear resistance and the centrality of treatment parameters in the different apparatus and kicked the bucket materials. It was identified that 
cryogenic treatment induces approximately $110 \%$ improvement in tool life.

Exploratory studies have uncovered that cryogenic treatment connected to cutting instruments enhances mechanical properties, for example, work piece surface harshness, homogeneous carbide circulation, hardness, and durability. However, sufficient information about the application of cryogenic treatment to cutting tools lacks especially with specific reference to deep cryogenic treatment. In addition, the cryogenic handling application framework has a high introductory speculation cost, which is a detriment regarding the materialness of the procedure. Various gases such as helium, oxygen, nitrogen, and neon are used for cryogenic treatment [11-13]. Nitrogen constitutes a significant bit $(78.03 \%)$ of the atmosphere, and liquid nitrogen, the most ordinarily utilized gas as a part of cryogenic treatment applications [14-16].

Although there is sufficient literature available, still it is not clear whether deep cryogenic treatment enhances the wear resistance of some specific steels as studies conducted elsewhere significantly focused on general cryogenic treatment. Therefore, this review aimed to explore the studies conducted on deep cryogenic treatment and identify the gap for the future studies. The paper is organized as takes after: section 2 presents the idea of cryogenic treatment and profound cryogenic treatment while this is trailed by the cryogenic framework and sorts of cooling framework. In Section 3 performance analysis of past work is given. Finally, the section 4 summarizes the findings and conclude the paper.

\section{Cryogenic Treatment}

The liquid nitrogen that is generated from the nitrogen plant is kept in storage vessels. Then, transfer lines are used to direct the same to a closed vacuum evacuated chamber that is known as cryogenic freezer with the help of a nozzle. The supply of liquid nitrogen into the cryo-freezer is subjected to operation with the help of solenoid valves. The gradual takes place inside the chamber at a rate of $20 \mathrm{C} / \mathrm{min}$ from the room temperature to a temperature of $-1960 \mathrm{C}$. Once it attains the sub-zero temperature, specimens are transferred to the nitrogen chamber or soaking chamber, in which they are stored for 24 hours while supplying liquid nitrogen continuously. There are three significant elements of the cryogenic treatment process, as obtained from the research conducted in the Mechanical Engineering Department at Louisiana Tech University. Those elements are a very slow cool down from ambient temperature to cryogenic temperature, a long soak at cryogenic temperatures, and a triple heat temper after the cryogenic treatment.

Several studies have been conducted previously on deep cryogenic treatment. In [17] the authors distinguished the cooling approach for most adequately and financially utilizing cryogenic machining. This study assessed cutting temperatures got under different cooling conditions where study connected liquid nitrogen (LN2) to cut Ti-6Al-4V, a difficult to-machine. In [18] performed a study by applying the LN2 jet while turning of AISI 4140 steel in the cutting zone and found higher surface roughness, limited tool wear and high dimension of accuracy when compared to dry and wet machining. Stewart [19] conducted cryogenic treatment into $\mathrm{C} 2$ tungsten carbide (WC-6\% Co) inserts and correlated to untreated carbide inserts in a medium density fibreboard (MDF). Reddy et al. [20] determined the impact of deep cryogenic treatment over the chemical vapor deposition (CVD) coated over carbide ISO P-30 inserts in the machining process of $\mathrm{C} 45$ steel. Arrazola et al. [21] assessed an apparatus wear mechanisms when machining Ti5553. Vadivel and Rudramoorthy [22] in the turning of nodular cast iron evaluated the microstructure of cryogenically treated $(\mathrm{TiCN}+\mathrm{A} 12 \mathrm{O} 3)$ and the untreated inserts and found that the treated and coated carbide inserts had better significance that untreated (UT) carbide tools.

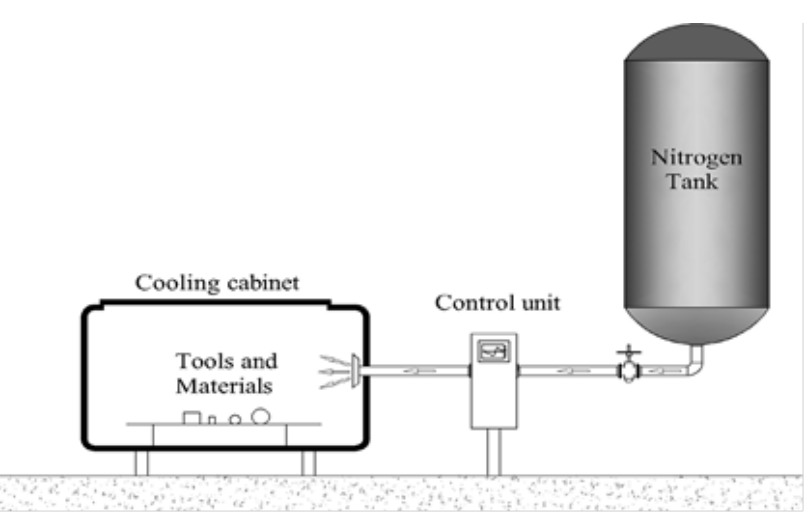

Fig. 1 Schematic presentation of cryogenic treatment applied in a controlled manner

This section reviews the particular studies on theeffect of profound cryogenic treatment on Titanium. Gill et al. [23] upgraded the impacts of shallow and profound cryo-treated carbide devices in C-65 steel turning. Based on preliminary turning tests, the cutting speed was differed in four additions: $110,130,150$, and $180 \mathrm{~m} / \mathrm{min}$. All the cutting tests were performed at a depth of cut of $1 \mathrm{~mm}$ and feed rate of 0 . $1 \mathrm{~mm} / \mathrm{rev}$. The cryogenic treatment appeared to be effective in reducing surface harshness for relatively longer machining times. Cryogenic treatment object crystal structure changes in both the soft and hard binder phase of tungsten carbide which, alongside the precipitation of phase carbides, might have been in charge of the upgraded cutting existence of the cutting supplements.

Armendia et al. [24] examined that single-point tool life analysis and a Orthogonal cutting force measurements to evaluate the response to heat treatment by machining on three titanium alloys namely Ti6246, Ti-5Al-4V-0. 6Mo-0. 4Fe (TIMETAL1 54M) and Ti6A14V. The TIMETAL154M indicated higher performance than the regular Ti6A14V of a tool life of 15 minutes with a $20 \%$ maximized allowable cutting speed. The Ti6246 alloy indicated the highest cutting forces and higher tool wear rates in various heat treatment settings due to its durable mechanical properties. A recently developed allow with identical mechanical properties of Ti6A14V called the TIMETAL1 54M alloy, indicated lower wear rates. In machining of alloys, there had been microstructural variations as an effect of heat treatment. The $\mathrm{b}$ annealed samples of the When TIMETAL1, and Ti6A14V $54 \mathrm{M}$ combinations were taken and $\mathrm{b}$ annealed, with a fine lamellar microstructure, demonstrated impressive high cutting forces and short tool life. Whereas the other heat treatments indicated no major impact on the machinery behavior of the evaluated alloys as it produced no microstructural developments. The Ti6246 alloy indicated shorter tool life and high cutting force measurements in the tested body. The test outcomes indicated better mechanical properties of the alloy when correlated to TIMETAL154M and Ti6A14V alloy. 
Dhananchezian et al. [25] examined the effect of LN2 cooling while turning of AISI 304 stainless steel using modified tungsten carbide tool inserts. The impact of liquid nitrogen as a coolant connected through holes made on the rake and flank surfaces of the PVD TiAlN covered tungsten carbide turning apparatus additions of ISO CNMG 120412 MP-KC5010 on the turning of AISI 304 stainless steel is concentrated. The impact of cryogenic cooling on the cutting temperature, surface roughness, cutting force, and device wear has been contrasted and those of wet machining. It is watched that in the cryogenic cooling strategy, the cutting temperature was diminished by $44-51 \%$ the cutting force was decreased to a gre of $16 \%$, and the surface roughness was reduced by $22-34 \%$ over that of wet machining. Cryogenic cooling utilizing liquid nitrogen decreased tool wear through the control of temperature-dependant wear mechanisms.

Senthilkumar and Rajendran [26] illustrated a study on L27 Taguchi orthogonal design with the parameters of deep cryogenic treatment to attain a minimum wear loss of 4140 steel. Hardening temperature (A), soaking period (B), tempering temperature $(C)$, and tempering period (D) are the four distinguished process parameters included for the optimization study. The communications among these factors are also determined. In the deep cryogenic treatment method the most important factor was the hardening temperature at a percentage of $17.34 \%$ at $8880 \mathrm{C}$. It was also determined that interactions between the hardening temperature vs. tempering temperature $(\mathrm{AxC})$ and soaking period $(2.32 \%)$ vs. tempering period $(2.35 \%)(\mathrm{BxD})$ has been more vital than any other factors.

Ravi and Kumar [27] organized an investigation on the impact of cryogenic cooling using liquid nitrogen (LN2) jet in the performance of milling in hardened AISI D3 tool steel using TiN-coated carbide inserts. The test was conducted at a stable speed of $125 \mathrm{~m} / \mathrm{min}$ at three various feed rates at the range of 0.01 to $0.02 \mathrm{~mm} /$ tooth. In the process of LN2 machining. The cutting temperature was limited to $43-48 \%$ and $22-39 \%$ in dry and wet machining. The outcomes demonstrate that machining with LN2 lowers cutting temperature, tool flank wear, cutting forces and surface roughness as compared with wet and dry machining. With LN2 cooling, it has been found that the cutting temperature was diminished by $57-60 \%$ and $37-42 \%$; the apparatus flank wear was lessened by $29-34 \%$ and $10-12 \%$; the surface harshness was diminished by $33-40 \%$ and $25-29 \%$ compared to wet and dry machining. Contrasted with dry and wet machining the cutting forces likewise diminished respectably. This can be ascribed to the way that LN2 machining gives better cooling and lubrication through a substantial reduction in the cutting zone temperature.

Reddy and Ghosh [28] explores the negative side of cryo technology for a situation study, where hardened bearing steel (AISI 52100) was ground by an alumina wheel with frozen N2 in both gas and liquid (LN2) jet form. Elemental analysis of the sample was carried utilizing Optical Mission Spectroscope (OES) - 1960C is the temperature. The machine tool used is Reciprocating surface grinder. It was watched that the ground specimen endured a huge dimensional deviation with the liquid jet as for dry and soluble oil environment. In a comparative manner, microhardness of workpiece strikingly was changed thus was the deterioration of surface finish. On the contrary, Gratio was found to be remarkably improved, which is in line with information about the available literature. The extent of those adverse effects could be controlled by using chilled N2 gas instead of LN2 jet however with a compromise on Gratio.

In this Gill et al. [23] talked about the improved the instrument life in theinterrupted machine under the cooling conditions. Armendia et al. [24] examined about the single point analysis of the orthogonal cutting. Senthilkumar and Rajendran [26] studies on L27 Taguchi orthogonal design with the parameters of deep cryogenic treatment to attain a minimum wear loss. Dhananchezian et al. [25] also studied about the LN2 cooling but by using the tool AISI 304. Ravi and Kumar [27] impact of cryogenic cooling using liquid nitrogen (LN2) jet in the performance of milling in hardened AISI D3 tool steel using TiN-coated carbide inserts. Reddy and Ghosh [28] explores the negative side of cryo technology for a situation study, where hardened bearing steel (AISI 52100) was ground by an alumina wheel with chilled N2 in both gas and liquid (LN2)

\section{A. Cryogenic System}

A cryogenic system is an equipment that allows cooling temperature, (i. e. cooling and heating rate), particularly cooling in the cryogenic reach in a chamber utilizing cryogenic liquid like fluid helium or nitrogen. Amid The sixties, Cryogenic treatment was finished by direct inundation into fluid nitrogen, which created a disastrous consequence of splitting the segments. Be that as it may, later, the cryogenic treatment framework created by Ed Busch (Cryo-Tech, Detroit, MI) in the late 1960's and later improved by Peter Paul in with a temperature feedback control on cooling and heating rate which, prevented sudden temperature changes and led to the development of efficient CT process.

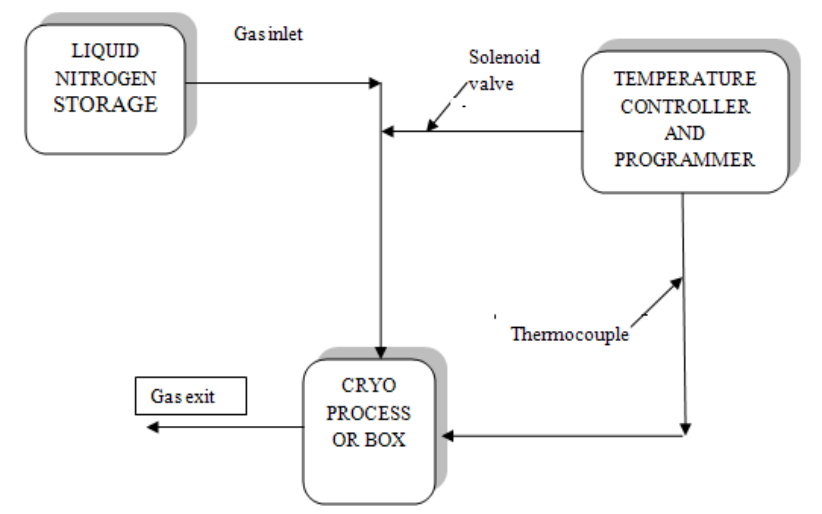

Fig. 2 Cryogenic Treatment Procedures

Profound cryogenic treatment is a sparing perpetual treatment that effects the mechanical parts of the steel segments. The percentage of retained austenite contained by the conventional treatment of steel is lessened by the process of deep cryogenic treatment. The elimination of retained austenite and the cleansing of carbide particles are the main causes of the wear resistance enhancement. By using deep cryogenic treatment method, the fragments are slowly cooled from room temperature to $1960 \mathrm{C}$ and are soaked for around 12 to 24 hours at $1960 \mathrm{C}$, and later reheated slowly again to the room temperature continued by tempering. Charles and Arunachalam [29] indicated that the cryogenic treatment is a homogenous process and needs to be conducted only once that offers major significance in the productive and functional life of steel components such as gears, engines, machine parts, brake rotors, and transmission to gun barrels, machine tools. 


\section{B. Category of Cryogenic Treatment}

A basic distinction among different $\mathrm{CT}$ is given by the parameters of the cooling-warming cycle. In [30] two families relying upon the minimum temperature reached during the cycle are classified:

Shallow Cryogenic Treatment (SCT) or Subzero Treatment: the specimens are placed in a freezer at $193 \mathrm{~K}$ and then they are exposed to room temperature.

Deep Cryogenic Treatment (DCT): the specimens are slowly cooled to $77 \mathrm{~K}$, held-down for many hours and gradually warmed to room temperature.

In [31], the Taguchi Design of Experiment (DOE) method is applied to identify and to optimize the critical parameters of DCT on an $18 \% \mathrm{Cr}$ martensitic stainless steel used for piston rings. The Analysis of Variance (ANOVA) of wear test outcomes has brought up that the most noteworthy element has been the drenching temperature ( $72 \%$ in commitment), trailed by the splashing time (24\%) and the cooling rate $(10 \%)$. Little significance $(2 \%)$ for the temperature of the treating process performed after DCT has been watched, while the treating time is developed as an immaterial parameter. Practically zero hugeness for parameters connections has been computed and at last the creators have gotten an ideal mix of $89 \mathrm{~K}$ dousing temperature, 36 hours drenching time, $1 \mathrm{~K} / \mathrm{min}$ cooling rate and 1 hour treating at $523 \mathrm{~K}$, anticipating a wear loss of 2 . $26 \mathrm{mg}$ (95\% in confidence). A test performed on tests treated with these parameters has affirmed the outcome.

\section{Effects on the Material Microstructure}

The microstructure of examples demonstrates the adjustment in dispersion of hastens, there are two classes they are Ferrous Alloys and Non-Ferrous Alloys, the point of interest depiction on these classification is given underneath.

Ferrous Alloys: As indicated by the writing about cryotreated instrument steels, the change of mechanical properties can be attributed to distinctive marvels; Complete change of the held austenite into martensite; Fine scattered carbides precipitation; and Removal of remaining hassles. It is realized that all steels at $193 \mathrm{~K}$ change the austenite into martensite. The utilization of cool treatment has been at first created on martensitic apparatus steels to uproot held austenite with advantages on hardness.

A diminishment from $5.7 \%$ to $4.2 \%$ in held austenite volume has been measured after DCT by the utilization of neutron diffraction on AISI 4340 steel [32]. The temperature came to in SCT is sufficient to get this outcome, along these lines the utilization of a lower temperature by DCT must be supported on the off chance that it actuates some distinctive marvels which prompt a further change of the mechanical properties. In [33], a lessening in held austenite portion and a pole like carbides precipitation amid treating after DCT have been watched, bringing up a relationship between's the carbide measurement and the treating temperature. In addition the creators have gotten a more prominent dimensional strength of DCT parts after each ensuing treating, which come about entirely identified with the held austenite disposal, on account of the lower volume contrasted with the martensite. The dimensional soundness is a sought property for some precise applications as worn fitting gages [34]. The X-beam diffractometric perceptions did in [35] have affirmed both wonders: $25 \%$ of the held austenite saw before DCT treatment has been changed into martensite and fine carbides precipitation has been advanced. The majority of the creators, particularly in late papers, have conceded to crediting to the fine carbides precipitation the change of the wear conduct.

As per the writing, an entirely unexpected component happens amid CT of austenitic stainless steels. The effect of DCT on welded cruciform joints of AISI 304L austenitic stainless steel has been inspected in $[36,37]$ : the break start life has been stretched out by strain-impelled martensite framed amid CT. Likewise, the creators have watched an alternate lingering stress arrangement close to the welded metal after DCT: the ductile remaining hassles have been mitigated and a compressive anxiety field has been prompted as an outcome of extension of the weld metal amid this change. While in [38] the authors have found a slight decrease of $\mathrm{m}$ and $\mathrm{C}$ Paris constants after DCT, indicating a reduction in crack growth rate, the result has not been confirmed in [39] by the same authors. In the talk about break start life augmentation, the writers have recommended a disengagement sticking system in concurrence with the TEM perception and with the diffractometric examination performed in [40-42], which have uncovered the vicinity of nano martensitic particles in pre-strained austenitic stainless steels after a SCT performed with a couple of hours holdtime at $3 \mathrm{~K}$ above Ms (martensite begin temperature).

Non-Ferrous Alloys: In spite of the commercial on cryoorganizations sites, which guarantees improvement on an extensive variety of materials, there are few papers in writing about CT of nonferrous materials. In [43], the DCT consequences for an extensive variety of polymers and composites have been tried, bringing up intriguing results for some of them. Utilizing X-beam diffraction the creators have discovered a minor increment in cristallinity after the DCT on Poly ether imide (PEI) and on Polyimide (PI), while no progressions have been distinguished on Poly tetra fluoro ethylene (PTFE). The adjustment in cristallinity of PEI has been affirmed by Differential Scanning Calorimetry (DCS), which has demonstrated an increment of the glass move temperature $(\mathrm{Tg})$ from $488 \mathrm{~K}$ to $526 \mathrm{~K}$. The makers have related the augmentation in wear resistance of PEI and of PI to the alteration in cristallinity. In addition, Scanning Electron Microscopy (SEM) has called attention to a rougher geology for the surface of the cryo treated PEI. Keeping in mind the end goal to clarify these perceptions, the creators have proposed the advancement of remaining burdens in the polymer as an aftereffect of the constriction at cryogenic temperatures and consequent uneven development amid the warming stage. On account of the PTFE, the change in wear conduct after the DCT has been credited to the hardness upgrade. Moreover, the SEM perceptions of PTFE powder have demonstrated agglomeration and fibrillation marvels after DCT, which the creators have identified with the flexible conduct, at low temperature as well, of PTFE.

Any critical or distinguishable changes in measurement, cristallinity, rigidity and extension on Ultra-High Molecular Weight Polyethylene (UHMWPE) tests after DCT have been found in [44].

The warmth influenced zone of an unspecified aluminum combination, which has been welded with Variable Polarity Plasma Arc (VPPA) system, has been examined previously, then after the fact DCT in [45]. Utilizing X-beam diffractometry, the creators have identified a decrease in remaining burdens, yet no microstructural investigation has been performed. DCT has additionally been performed on 7075 aluminum combination tests [46], however the creators 
did not discover any upgrade in pliable, effect and hardness properties and no further investigation about the material structure has been completed.

D. Effects on the Mechanical Properties

A broad accumulation of CT test outcomes is accounted for in $[47,48]$ concerning hardness and wear resistance of an extensive variety of steel levels. This arrangement of papers speaks to a breakthrough in the CT field. The papers $[49,50]$ show wear and hardness results for separately twelve apparatus steels, three stainless steels and four different steels. By contrasting the outcomes acquired and $189 \mathrm{~K} \mathrm{SCT}$ and $77 \mathrm{~K} \mathrm{DCT}$, the creators have watched a noteworthy grating resistance increment for the apparatus steels subjected to the colder treatment, while the stainless steels have demonstrated a distinction of under $10 \%$ and the arrangement carbon and the cast iron did not enhance with either SCT and DCT.

After the examinations completed in paper [51] numerous works reporting test results on CT materials have been distributed, however everyone has concentrated on one or on couple of materials as opposed to gathering information from a significant number of them. As an outcome, it can be useful to compress the distributed results keeping in mind the end goal to have a general photo of the deliberate impacts. The major mechanical properties are as follows:

$\begin{array}{ll}\circ & \text { Hardness } \\ \circ & \text { Tensile and Bending Strength } \\ \circ & \text { Yield strength } \\ \circ & \text { Fatigue life } \\ \circ & \text { Toughness } \\ \circ & \text { Wear resistance }\end{array}$

A brief exchange about consequences for every property is proposed in the accompanying sections.

Hardness: Many hardness tests about CT are accounted for in writing on the grounds that this property is identified with the wear resistance. Hardness properties are typically measured through space tests and they are communicated in distinctive scales relying upon the penetrator shape. The most utilized routines are the Rockwell and the Vickers ones. While the first strategy is a large scale space test, the second one can be performed both as full scale or smaller scale space, contingent upon the connected burden, as performed in [38, 39]. The hardness of apparatus steel is primarily impacted by held (delicate) austenite and along these lines CT can assume an essential part. On the other hand, when contrasted with wear results, hardness test results (see Table 4), show that the components can be distinctive for diverse materials. For example, in [52] a little increment $(+0.13 \%)$ in hardness has actuated a $51 \%$ in wear rate for AISI M2 and the creators have reasoned that AISI M2 wear resistance change can be credited to hardness increment. The same test on AISI H13 instrument steel has demonstrated a change of $6.9 \%$ in hardness identified with a reduction of $29 \%$ in wear rate and, as per the creators, the wear resistance change has been related to the improved sturdiness of the CT material. The paper [33] proposes that playing on carbides part and measurement and on held austenite permits to accomplish an advanced proportion in the middle of hardness and sturdiness in rapid steels.

Intriguing results on HSS base composites fortified with $\mathrm{Nb}$ and $\mathrm{Ta}$ carbides have been acquired, with around 10\% expanded hardness [53]. Concerning non-ferrous materials, no significant changes in hardness of aluminum alloys [45, 46] and of Ultra-high Molecular Weight Polyethylene [44] have been detected, while PTFE, PEI, PI, PC and PU have shown important changes in Shore D hardness [43].

Tensile and Bending Strength: A couple of malleable and twisting test outcomes have been distributed looking at properties prior and then afterward CT. This is fundamentally because of the way that tractable properties are less pertinent than hardness and wear resistance in instrument steels, which are the most considered materials in the CT writing. Besides, static properties are required to be not unequivocally influenced by held austenite division, while concerning precipitation fortifying it is gathered that little encourages can be effortlessly avoided at high push levels by the disengagement climbing system. Notwithstanding, the main distributed results about instrument steel allude to AISI M2 and T1 and demonstrate an astounding change of around $20 \%$ and of $25 \%$ separately in bowing quality [54]. In [55], an expansion from $7 \%$ to $16 \%$ in rigidity of 4140 frosty moved steel examples has been recognized after $\mathrm{CT}$.

In [56], a slight diminishment in rigidity has been measured for a carburized steel-815M17 subjected to CT, contrasted with the same material traditionally treated. Specifically the creators have watched a lessening of $1.5 \%$ for SCT and of $9.34 \%$ for DCT. The cryogenic treatment does not appear to be successful on ductile properties of AISI 304 and 316 stainless steels [40-42]. No significant changes in tensile properties have been detected on aluminum alloys [45, 46] and on UHMWPE [44].

Fatigue Resistance: Fatigue of materials has been a standout amongst the most critical examination points from the earliest starting point of the twentieth century until today in the region of materials and mechanical designing. All the above recorded CT microstructural changes are identified with the weariness conduct, somebody with advantageous impacts and different ones with inconvenient impacts. A field of fine hard carbides or the vicinity of nano-sized martensite in an austenitic lattice can be the powerful components in postponing or blocking disengagements movement at low push sufficiency, when separation climbing is unrealistic to show up. Starting here of perspective, from one viewpoint the watched DCT fine carbides precipitation can prompt a delayed break nucleation stage. On the other hand, the held a portion of bendable austenite can go about as a split arrestor in the spread stage and after that its diminishment could detrimentally affect the last phase of weariness. Moreover, the remaining hassles too assume an essential part in break nucleation system, specifically amid the twisting exhaustion. Therefore it is important to weigh up every one of these impacts, all together to understand the fatigue results.

In spite of their awesome significance in numerous mechanical applications, exhaustion properties of CT steels have not been examined by numerous creators [57] is the most seasoned paper found in writing about low temperature treatment and weariness quality. The creators have subjected a chilly moved steel to two diverse DCT: a fast treatment by direct drenching in fluid nitrogen for 60 minutes, a moderate treatment by controlled cooling and 30 minutes holding time. Twisting weakness test results on treated and nontreated examples have demonstrated no distinctions in mean estimations of weariness cutoff, yet a littler scattering for DCT tests has been found. Also, the creators have completed 
an acoustic spectra investigation finding clear contrasts in the adequacy of sounds of DCT examples, however no microstructural changes have been recognized in metallographic and fractographic reviews. Thus the creators have proposed a remaining burdens impact, assuming an association with the redistribution of the grid deformities.

A few learns about $\mathrm{CT}$ and exhaustion have been led at the Precision and Intelligence Laboratory of the Tokyo Institute of Technology [40-42]. During these researches the creators have measured the Ms (martensite begin temperature) of a stainless steel with the acoustic outflow strategy, then they have cooled the specimens only $3 \mathrm{~K}$ above Ms and they have given back the examples to the room temperature. In [40] the test has been led on an austenitic $\mathrm{Fe}-18 \mathrm{Cr}-8 \mathrm{Ni}$ stainless steel pre-strained by $2 \%$ so as to build the disengagement thickness.

A slight build (25-30 MPa on around $600 \mathrm{MPa})$ in weariness limit has been additionally measured in [40] for the turning weakness test on AISI 4340 steel. The creators have credited this outcome to the slight increment in hardness, yet they didn't propose any microstructural instrument for the clarification of the wonder. Concerning non-ferrous materials, a high-cycle exhaustion test has been performed at room temperature on an unspecified aluminum composite as-welded and cryo-treated, which has not demonstrated a detectable change [45].

Thermal Fatigue Resistance: In numerous designing applications, specifically for inside burning motors, the blend of warm and mechanical cycles is an ordinary operational prerequisite and consequently it could enthusiasm to perform an investigation of CT consequences for the thermo mechanical exhaustion conduct of materials. In any case, the main study which has been distributed up to this point is a preparatory test about impact of DCT on unadulterated warm weakness properties, without mechanical burdens [58]. By subjecting a turning plate to a cyclic impelling warming and water-cooling (from $353 \mathrm{~K}$ to $973 \mathrm{~K}$ ) a break system has been produced on its surface In the wake of measuring the warm break thickness, the mean split length $1 \mathrm{~m}$ and the greatest break length Pmax, the creators have computed the pyrocracking variable $\mathrm{C}$ as the result of these qualities. The DCT plate has demonstrated a pyrocracking element of $0.6 \mu \mathrm{m}$ against $1.18 \mu \mathrm{m}$ of the untreated one. The parameter in charge of this diminishing has been the break thickness, which has lessened from 3. 49 $\mathrm{mm}-1$ to $1.53 \mathrm{~mm}-1$. The mean break length and the most extreme split length have remained just about the same for DCT and non-DCT tests, driving the creators to reason that DCT can defer the break nucleation process without expanding the spread.

Fracture Toughness: Break sturdiness is a measure of the breaking resistance of a material which contains a split. Together with the exhaustion conduct, break durability is one of the keys of the arrangementutilizations of the most recent century. As specified in the Fatigue Resistance passage, held bendable austenite portion can assume the part of split arrestor in martensitic steels, improving the sturdiness. In [33], the creators have recommended that carbides portion and measurement and held austenite part assume an essential part in the advancement of the proportion in the middle of hardness and durability of fast steels.
Wear Resistance: Wear resistance speaks to a vital property of a material when it is utilized as a part of utilizations that prompt equal moving of in-contact segments, for example, machining devices, course, equips, brake rotors, cylinder seals, and so forth. Among the recorded above microstructural changes identified with CT, both held austenite diminishment and carbide precipitation can prompt a change in wear resistance by the expansion of the steel hardness. It is verging on difficult to do a complete correlation between the outcomes acquired in writing, due to distinctive test conditions, (for example, sliding speed, remove or connected burden) utilized by the writers and diverse wear markers reported as results (i. e. wear resistance or wear rate).

The most tested impact of CT is the improvement of the wear resistance, particularly on instrument steels. The wear resistance change reported in writing, after the distributions [47-51] about distinctive materials and test setup. Distinctive setup are accounted for in writing for wear test, however the most utilized arrangement is the pinon plate, as indicated by the ASTM benchmarks and the outcomes are typically reported as far as wear resistance or of wear rate. A couple of inventors have in like manner performed tests direct on cryotreated instruments, by measuring the gadget life in number of worked pieces, in the indicated "flank-wear test" or in the "turn drill test".

As it is showed up in writing a standout amongst the most cryo-tried materials is AISI M2 rapid apparatus steel, which is generally utilized for drills, processing cutters and different instruments. Wear resistance is an essential property for instruments, as well as for some parts subjected to moving or sliding contact, in distinctive modern fields like car, mining, oil boring, and so on. A few learns about impacts of $\mathrm{CT}$ on bearing steels and carburized steels utilized as a part of car commercial enterprises are accessible in writing (i. e. En353 has a critical application for crown wheel, crown pinion, slant pinion, slant wheel, timing gears, lord pinion, pinion shaft).

Numerous creators concur with [59] about the reason of the wear resistance change: it is the fine carbides precipitation that improves quality and sturdiness of the martensite network, instead of the diminishment or the disposal of the held austenite part. In $[52,60]$, the wear rates of an AISI M2 tool steel have been thought about after four different treatment combinations and sequences:

- $\quad$ Quenching then double tempering (A);

- Quenching, double tempering then DCT (B);

- $\quad$ Quenching, DCT then tempering (C);

- Quenching, DCT then double tempering (D).

The (B) tests have demonstrated a diminishment of 51\% in wear rate contrasted and the (An) examples, against 40\% and $35 \%$ for (C) and (D) examples separately. The creators have presumed that more noteworthy advantages are gotten when DCT is completed in the wake of treating procedure.

Another intriguing examination has been proposed in [10] between cryo-treated and TiN covered examples, which has demonstrated that $\mathrm{CT}$ for 24 hours at $93 \mathrm{~K}$ is more successful on wear resistance than TiN covering. Through the correlation of the aftereffects of CT examples treated with distinctive parameters, the creators have additionally presumed that the instrument in charge of the wear resistance change is basically an isothermal procedure and the dousing time is more vital than the base temperature came to amid the treatment. Also, they have observed CT to 
be more advantageous on untempered than on tempered examples.

The impact of the dousing temperature on DCT wear change has been affirmed in [31]. As indicated by [43], the wear resistance of some designing polymers and composites can be enhanced by DCT. The creators have acquired an increment up to $60 \%$ in rough wear resistance of cryotreated PTFE, while PEI and PI have indicated upgrades up to $35 \%$ and $58 \%$ separately. Specifically, the paper concentrate on the diverse reactions to DCT, which have been acquired for the same polymeric grid joined with distinctive amouts and characteristics of strands or fillers. As an illustration, a $+30 \%$ in wear resistance have been accounted for cryotreated PEI without fiber support, while the same material $40 \%$ glass filaments strengthened have demonstrated a $-35 \%$ in wear execution after DCT. Some interesting results have been represented, in the same paper, for Polyetherimide Copolymer, for Polyurethane (PU) and for Polycarbonate.

\section{E. Recent Research based on the Wear Resistance}

This section reviews the studies on deep cryogenic treatment on wear resistant. Kaushal et al. [61] evaluated about Microstructure and Hardness, after Cryogenic treatment comparison is also made with untreated test specimen. The study adopted temperature of about $-1960 \mathrm{C}$ by using the tool steel AISI- D2. The study findings revealed that hardness in creased after cryogenic treatment in comparison with untreated also change in the micro- structure was observed due to phase transition from austenite to martensite which also altered the various properties of tool AISID2steel.

Jandová et al. [62] investigated the impact of a deep cryogenic treatment on the wear resistance and microstructure of the X37CrMoV5-1 (H11) hot-work steel. The wear resistance was measured at $400{ }^{\circ} \mathrm{C}$ using the pinon-disc method with a rotary tribometer. The microstructure of the steel was examined using light and transmission electron microscopes. The studyM discoveries uncovered that a microstructural perception in a light magnifying lens did not uncover any considerable contrasts between the examples solidified in the customary way and the examples after a profound cryogenic treatment. On the other hand, the analysis of specimens upon deep cryogenic treatment by means of transmission electron microscopy found two types of substructure, which are likely to facilitate the precipitation of fine carbides during the final tempering of the steel. At this point, the impact of longer holding times at the deep cryogenic temperature on this substructure has not been analyzed. The cause of the decline in the wear resistance with extended holding times cannot thus be determined.

Ather and Sonawane [63] aimed to reveal the enhancement of wear resistance of AISI D3 Tool Steel by Cryogenic Treatment. In the experimentation process, tests of AISI D3 instrument steel were taken in clusters out of which a few specimens were treated with traditional warmth treatment (QT) while other were cryogenically treated (QCT) at $77 \mathrm{~K}$ for a time of $24 \mathrm{hrs}$. The study findings revealed that there is an increase in wear resistance of AISI D3 material after performing the cryogenic treatment. Yet, this increase varied from few percent too few hundred percentage. Therefore depending upon the load conditions, cryogenic treatment should carry out or not. In [62] Jandová et al. investigated procedure and the results of exploring the impact of a deep cryogenic treatment on the wear resistance and micro structure of the X37CrMoV5-1. Ather and Sonawane [63] revealed the enhancement of wear resistance of AISI D3 Tool Steel by Cryogenic Treatment. Kaushal et al. [61] evaluated about Micro- structure and Hardness, after Cryogenic treatment comparison is also made with untreated test specimen.

\section{Performance Analysis}

The performance of the various past work on the cryogenic treatment is given in the table 1 .

Table 1 Performance Analysis of Past Work

\begin{tabular}{|c|c|c|c|c|c|}
\hline Author & Objective & $\begin{array}{l}\text { Property } \\
\text { Type }\end{array}$ & Tools & $\begin{array}{l}\text { Cryogenic } \\
\text { temperature } \\
\text { and period } \\
\left({ }^{0} \mathrm{C}\right)\end{array}$ & Results \\
\hline $\begin{array}{l}\text { P.J. Arrazola et } \\
\text { al. [21] }\end{array}$ & $\begin{array}{l}\text { To understand tool wear } \\
\text { mechanisms when } \\
\text { machining Ti555.3. }\end{array}$ & Titanium & Ti555.3, Ti6Al4V & 400 & $\begin{array}{l}\text { the machinability could be } \\
\text { approximately } 56 \%\end{array}$ \\
\hline $\begin{array}{l}\text { K. Vadivel, et al. } \\
{[22]}\end{array}$ & $\begin{array}{l}\text { analyses the performances } \\
\text { of CT coated carbide } \\
\text { inserts and untreated coated } \\
\text { carbide inserts in turning of } \\
\text { nodular cast iron }\end{array}$ & $\begin{array}{l}\text { wear } \\
\text { resistance }\end{array}$ & PUMA 240L & -196 & $\begin{array}{l}\text { wear resistance of cryogenically } \\
\text { treated coated carbide inserts is higher } \\
\text { than that of the untreated ones }\end{array}$ \\
\hline Gill et al. [23] & $\begin{array}{l}\text { the effects of shallow and } \\
\text { deep cryo-treated carbide } \\
\text { tools in C- } 65 \text { steel turning }\end{array}$ & Titanium & $\begin{array}{l}\text { deep cryo-treated } \\
\text { carbide }\end{array}$ & $\begin{array}{l}110,130,150 \\
\text { and } 180 \mathrm{~m} / \mathrm{min}\end{array}$ & Enhanced tool life \\
\hline $\begin{array}{l}\text { Armendia et al. } \\
\text { [24] }\end{array}$ & $\begin{array}{l}\text { single-point tool life } \\
\text { analysis and an Orthogonal } \\
\text { cutting force measurements }\end{array}$ & Titanium & $\begin{array}{l}\text { Ti6246, Ti-5Al-4V- } \\
0.6 \mathrm{Mo}-0.4 \mathrm{Fe} \\
\text { (TIMETAL1 54M) } \\
\text { and Ti6Al4V }\end{array}$ & $\begin{array}{l}54 \mathrm{M} \text { of } 15 \\
\text { minutes }\end{array}$ & $\begin{array}{l}\text { Ti6246 alloy indicated the highest } \\
\text { cutting forces and higher tool wear } \\
\text { rates in various heat treatment settings } \\
\text { due to its durable mechanical } \\
\text { properties }\end{array}$ \\
\hline $\begin{array}{l}\text { Dhananchezian } \\
\text { et al. }[25]\end{array}$ & $\begin{array}{l}\text { effect of LN2 cooling while } \\
\text { turning of AISI } 304 \\
\text { stainless steel using } \\
\text { modified tungsten carbide } \\
\text { tool inserts }\end{array}$ & Titanium & $\begin{array}{l}\text { TiAlN coated } \\
\text { tungsten carbide } \\
\text { turning tool }\end{array}$ & 304 & $\begin{array}{l}\text { Cryogenic cooling method reduced, } \\
\text { cutting temp., by } 44-51 \% \text {, cutting } \\
\text { force to max. of } 16 \% \text {, and surface } \\
\text { roughness by } 22-34 \%\end{array}$ \\
\hline $\begin{array}{l}\text { Senthilkumar } \\
\text { and Rajendran } \\
{[26]}\end{array}$ & $\begin{array}{l}\text { L27 Taguchi orthogonal } \\
\text { design to attain a minimum } \\
\text { wear loss }\end{array}$ & Titanium & L27 & 888 & $\begin{array}{l}\text { Interactions between the hardening } \\
\text { temperature vs. tempering temperature } \\
(\mathrm{AxC}) \text { and soaking period }(2.32 \%) \\
\text { vs. tempering period }(2.35 \%)(\mathrm{BxD}) \\
\text { has been more vital than any other }\end{array}$ \\
\hline
\end{tabular}




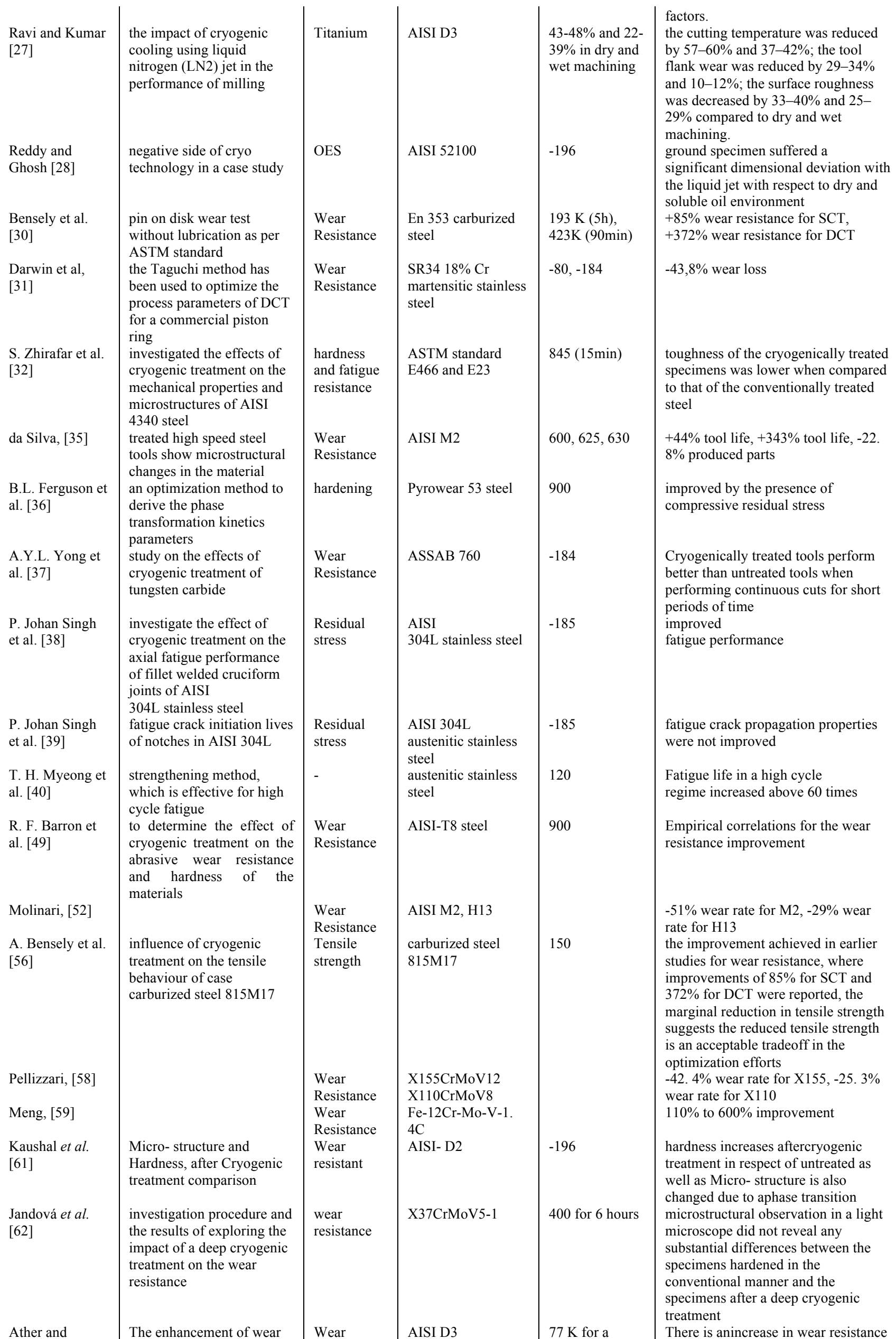




\begin{tabular}{|c|c|c|c|c|c|}
\hline Sonawane [63] & $\begin{array}{l}\text { resistance of AISI D3 Tool } \\
\text { Steel by Cryogenic } \\
\text { Treatment. }\end{array}$ & Resistance & & $\begin{array}{l}\text { period of } 24 \\
\text { hours }\end{array}$ & $\begin{array}{l}\text { of AISI D3 material after performing } \\
\text { thecryogenic treatment. }\end{array}$ \\
\hline Meng, [64] & & $\begin{array}{l}\text { Wear } \\
\text { Resistance }\end{array}$ & $\mathrm{Fe}-1.4 \mathrm{Cr}-1 \mathrm{C}$ & & $-50 \%$ wear rate \\
\hline Preciado, [65] & $\begin{array}{l}\text { effect of deep cryogenic } \\
\text { treatment on the hardness } \\
\text { and wear resistance of } \\
\text { carburized steels used in } \\
\text { gears was studied }\end{array}$ & $\begin{array}{l}\text { Wear } \\
\text { Resistance }\end{array}$ & Carburized steel & 200 & $-20 \%$ wear rate \\
\hline Yong, [66] & & $\begin{array}{l}\text { Wear } \\
\text { Resistance }\end{array}$ & $\begin{array}{l}\text { ASSAB } 760 \\
\text { medium carbon } \\
\text { steel }\end{array}$ & & $\begin{array}{l}-33 \% \text { flank wear after } 300 \text { s of } \\
\text { continuous cutting }\end{array}$ \\
\hline Yang, [67] & $\begin{array}{l}\text { effect of deep cryogenic } \\
\text { treatment on the matrix } \\
\text { structure and abrasion } \\
\text { resistance of high } \\
\text { chromium cast iron } \\
\text { subjected to destabilization } \\
\text { heat } \\
\text { treatment has been } \\
\text { investigated }\end{array}$ & $\begin{array}{l}\text { Wear } \\
\text { Resistance }\end{array}$ & $\begin{array}{l}13 \mathrm{Cr} 2 \mathrm{Mn} 2 \mathrm{~V} \text { high } \\
\text { Cr white iron }\end{array}$ & $\begin{array}{l}900,950,1000 \\
1050,1100 \text { and } \\
1150^{\circ} \mathrm{C}\end{array}$ & $+8 \%$ relative wear ratio \\
\hline Liu, [68] & $\begin{array}{l}\text { Effects of deep cryogenic } \\
\text { treatment on the } \\
\text { microstructure, hardening } \\
\text { behavior and abrasion } \\
\text { resistance of } \\
3 \text { Cr13Mo1V1.5 high } \\
\text { chromium cast iron }\end{array}$ & $\begin{array}{l}\text { Wear } \\
\text { Resistance }\end{array}$ & $\begin{array}{l}3 \mathrm{Cr} 13 \mathrm{Mo} 1 \mathrm{~V} 1.5 \\
\text { high } \mathrm{Cr} \text { cast iron }\end{array}$ & $400-650$ & $+5 \%$ relative wear ratio \\
\hline
\end{tabular}

Overall studies reviewed had focused to [23] enhance the tool life in interrupted machine under the cooling conditions, single point analysis of the orthogonal cutting [24], L27 Taguchi orthogonal design with the parameters of deep cryogenic treatment to attain a minimum wear loss. [26], LN2 cooling but by using the tool AISI 304, [25], and performance of milling in hardened AISI D3 tool steel using TiN-coated carbide inserts [27], enhancement of wear resistance of AISI D3 Tool Steel [63], and Micro- structure and Hardness [61] evaluated about, after Cryogenic treatment comparison is also made with untreated test specimen. Moreover, concentrates additionally analyzed the Further studies negative side of cryo innovation for a situation study, where solidified bearing steel (AISI 52100) was ground by an alumina wheel with chilled N2 in both gas and fluid (LN2) [20] while few researched strategy and the aftereffects of investigating the effect of a profound cryogenic treatment on the wear resistance and microstructure of the X37CrMoV5-1 [62]. From the review, it is found that cryogenic is applied to wear resistant, titanium, stainless steel and for metallurgical analysis. In future, the cryogenic can be applied to other components like gears, shaft and springs to improve their performance. In addition, it is observed that only a few reviews were made by considering CVD, OEM. The future work can also be done by considering tungsten carbide, HSS, PVD, CVD and OEM.

\section{Conclusion}

The According to the writing, the beginning doubt about CT impact on mechanical properties of materials seems, by all accounts, to be currently cleared up, particularly in the field of hardware steels. The most pertinent determinations through a writing examination can be abridged as; the cryogenic frameworks permit to control vital cycle parameters, for example, cooling rate, least came to temperature and drenching time. The decision of ideal treatment parameters requires particular examinations on every material, except on account of steels some helpful signs can be construed from distributed works. Wear resistance change have been generally affirmed by distributed papers, particularly by the ones concerning device steels. Beneficial effects of $\mathrm{CT}$ on toughness and fatigue behaviour have also been claimed by some authors. With couple of uncommon exemptions, no discernible consequences for ductile properties have been found in writing. In future the examiner need to think for the upgrades in wear resistance of PTFE, PI and PEI, further examinations about the impacts of $\mathrm{CT}$ on mechanical properties of composites and polymers could be an energizing investigation subject.

\section{References}

1. P. Baldissera and C. Delprete, Deep Cryogenic Treatment: A Bibliographic Review. Open Mechanical Engineering Journal, 2, 111 (2008)

2. S. Akincioglu, H. Gokkaya, and I. Uygur, A review of cryogenic treatment on cutting tools", The International Journal of Advanced Manufacturing Technology, 78 (9-12), 1609-1627 (2015).

3. K. D. Timmerhaus and R. P. Reed, Cryogenic engineering: fifty years of progress. New York: Springer Verlag, (2007).
4. I. J. Karassik, J. P. Messina, and C. C. Heald, Pump handbook", 4th Ed. [Online]. New York: McGraw-Hill Professional, (2008).

5. C. Machai, and D. Biermann, Machining of titanium-alloy Ti-10V2Fe-3Al under cryogenic conditions: Cooling with carbon dioxide snow. Journal of Materials Processing Technology, 211, 1175-1183 (2011).

6. E. Abele, and B. Schramm, Using PCD for machining CGI with a $\mathrm{CO} 2$ coolant system. Production Engineering, 2 (2), 165-169 (2008). 
7. L. De Chiffre, J. L. Andreasan, S. Lagerberg, and I. B. Thesken, Performance Testing of Cryogenic CO2 Cutting Fluid in Parting/Grooving and Threading Austenitic Stainless steels. CIRP Annals- Manufacturing Technolgy, 56 (1), 101-104 (2007).

8. B. Yalcin, A. Ozgur, and M. Koru, The effects of various cooling strategies on surface roughness and tool wear during soft materials milling. Materials and Design, 30 (3), 896-899 (2009)

9. H. Tsai, and H. Hocheng, Investigation of the transient thermal deflection and stresses of the workpiece in surface grinding with the application of a cryogenic magnetic chuck. Journal of Materials Processing Technology, 79 (1/3), 177-184 (1998).

10.D. Mohan Lal, S. Renganarayanan and A. Kalanidhi, Cryogenic treatment to augment wear resistance of tool and die steels. Cryogenics, 41, 149-155 (2001).

11. N. R. Dhar, S. Paul, and A. B. Chattopadhyay, The influence of cryogenic cooling on tool wear, dimensional accuracy and surface finish in turning AISI 1040 and E4340C steels. Wear, 249 (10-11), 932-942 (2001).

12. Jones DA, Lelyveld TP, Mavrofidis SD, Kingman SW and Miles NJ, Microwave heating applications in environmental engineering - a review. Resources, conservation and recycling, 34 (2), 75-90 (2002).

13. Kalsi NS, Sehgal R and Sharma VS, Cryogenic treatment of tool materials: a review. Materials and Manufacturing Processes, 25 (10), 1077-1100 (2010).

14. S. Kalia, Cryogenic Processing: A Study of Materials at Low Temperatures. Journal of Low Temperature Physics, 158 (5-6), 934-945 (2010).

15. V. Firouzdor, E. Netaji, and F. Khomamizadeh, Effect of deep cryogenic treatment on wear resistance and tool life of M2 HSS drill. Journal of Materials Processing Technology, 206 (1-3), 467472 (2008).

16.D. Thakur, B. Ramamoorthy, and L. Vijayaraghavan, Influence of different post treatments on tungsten carbide - cobalt. Materials Letters, 62 (28), 4403-4406 (2008).

17. S. Y. Hong, and Y. Ding, Investigation on wear behaviour of cryogenically treated TiAlN coated tungsten carbide inserts in Tturning. International Journal of Machine Tools and Manufacture, 51 (1), 25-33 (2001).

18. N. R. Dhar, S. Paul, and A. B. Chattopadhyay, Machining of AISI 4140 steel under cryogenic cooling - tool wear, surface roughness and dimensional deviation. Journal of Materials Processing Technology, 123 (3), 483-489 (2002).

19. H. A. Stewart, Cryogenic treatment of tungsten carbide reduces tool wear when machining medium density fiber board. Forest products Journal, 54 (2), 53-56 (2004).

20.S. T. V. Reddy, S. T. Kumar, V. M. Reddy, B. S. Ajaykumar, and R. Venkatram, Performance studies of deep cryogenic treated tungsten carbide cutting tool inserts on machining steel. Tribology - Materials, Surfaces and Interfaces, 2 (2), 92-98 (2008).

21. P. J. Arrazola, A. Garay, L. M. Iriarte, M. Armendia, S. Marya, and F. Le Maitre, Machinability of titanium alloys (Ti6A14V and Ti555. 3). Journal of Materials Processing Technology, 209, 2223-2230 (2009).

22.K. Vadivel, and R. Rudramoorthy, Performance analysis of cryogenically treated coated carbide inserts. The international Journal of Advanced Manufacturing Technology, 42 (3-4), 222-232 (2009).

23. S. S. Gill, J. Singh, H. Singh, and R. Singh, Investigation on wear behaviour of cryogenically treated TiAlN coated tungsten carbide inserts in turning. International Journal of Machine Tools and Manufacture, 51 (1), 25-33 (2011).

24. M. Armendia, P. Osborne, A. Garay, J. Belloso, S. Turner, and P. J. Arrazola, Influence of Heat Treatment on the Machinability of Titanium Alloys. Materials and manufacturing Processes, 27 (4), 457- 461 (2012).

25. M. Dhananchezian, M. P. Kumar, and T. Sornakumar, Cryogenic Turning of AISI 304 Stainless Steel with Modified Tungsten Carbide Tool Inserts. Materials and Manufacturing Processes, 56 (1) 781-785 (2011).

26.D. Senthilkumar, and I. Rajendran, Optimization of Deep Cryogenic Treatment to Reduce Wear Loss of 4140 Steel. Materials and Manufacturing Processes, 27 (5), 567-572 (2012).

27. S. Ravi, and M. P. Kumar, Experimental Investigation of Cryogenic Cooling in Milling of AISI D3 Tool Steel Materials. Materials and Manufacturing Processes, 27, 1017-1021 (2012).

28.PP. Reddy, and A. Ghosh, Effect of the Cryogenic cooling on Surface Quality of Ground AISI 52100 Steel. In 5th International and 26th All India Manufacturing Technology, Design and Research Conference, IIT Guwahati, India, 1-5 (2014).

29. S. Charles, and V. Arunachalam, Effect of particle inclusions on the mechanical properties of composites fabricated by liquid metallurgy. Indian Journal of Engineering and Materials Sciences, 10 (4), 301-305 (2003).

30.A. Bensely, A. Prabhakaran, D. Mohan Lal and G. Nagarajan, Enhancing the wear resistance of case carburized steel (En 353) by cryogenic treatment. Cryogenics, 45, 747-754 (2005).

31. Darwin JD, Lal DM and Nagarajan G, Optimization of cryogenic treatment to maximize the wear resistance of $18 \% \mathrm{Cr}$ martensitic stainless steel by Taguchi method. Journal of materials processing technology, 195 (1), 241-247 (2008).

32.S. Zhirafar, A. Rezaeian and M. Pugh, Effect of cryogenic treatment on the mechanical properties of 4340 steel. J. Mater. Process. Technol, 186, 298-303 (2007).

33. V. Leskovek and B. Ule, Influence of deep cryogenic treatment on microstructure, mechanical properties and dimensional changes of vacuum heat-treated high-speed steel. Heat Treat. Met, 3, 72-76 (2002).

34. I. A. Revis, A. M. Levinson, V. S. Naletov and S. A. Popov, Use of cryogenic treatment to restore worn plug gages. Chem. Petrol. Eng, 10 (5), 474 (1974).

35.F. J. da Silva, S. D. Franco, E. O. Ezugwu, and M. Souza Jr, Performance of cryogenically treated HSS tools. Wear, 261, 674685 (2006).

36. B. L. Farguson, Z. Li and A. M. Freborg, Modelling heat treatment of steel parts. Comp. Mater. Sci, 34, 274-281 (2005).

37. A. Y. L. Yong, K. H. W. Seah and M. Rahman, Performance evaluationof cryogenically treated tungsten carbide tools in turning. Int. J. Mach. Tool. Manu, 46, 2051-2056 (2006).

38. P. J. Singh, B. Guha and D. R. G. Achar, Fatigue life improvement of AISI 304L cruciform welded joints by cryogenic treatment. Eng. Fail. Anal, 10, 1-12 (2003).

39. P. J. Singh, S. L. Mannan, T. Jayakumar and D. R. G. Achar, Fatigue life extension of notches in AISI304L weldments using deep cryogenic treatment. Eng. Fail. Anal, 12, 263-271 (2005).

40. T. H. Myeong, Y. Yamabayashi, M. Shimojo and Y. Higo, A new life extension method for high cycle fatigue using micro martensitic transformation on an austenitic stainless steel. Int. J. Fatigue, 19 (1) S69-S73, (1997).

41. T. Ianamura, R. Abe, T. H. Myeong, M. Shimojo and Y. Higo, Fatigue life extension by nano-sized martensite particles in steels. in Proceedings of the 7th International Fatigue Congress, 633-638 (1999).

42. M. Shimojo and Y. Higo, Formation of nano sized martensite and its application to fatigue strengthening. in Amorphous and Nano cristalline Materials - Preparation, Properties and Applications, eds. A. Inoue and K. Hashimoto, Berlin: Springer, 186-204 (2001).

43. J. Indumathi, J. Bijwe, A. K. Ghosh, M. Fahim and N. Krishnaraj, Wear of cryo-treated engineering polymers and composites. Wear, 225-229, 343-353 (1999).

44. H. H. Trieu, L. H. Morris, M. E. Kaufman, R. Hood and L. S. Jenkins, Investigation of cryogenic treatment of UHMWPE. in Proceedings of the Sixteenth Southern Biomedical Engineering Conference, 90-91 (1997).

45. P. Chen, T. Malone, R. Bond and P. Torres, Effects of cryogenic treatment on the residual stress and mechanical properties of an aerospace aluminum alloy. in Proceedings of the 4th Conference on Aerospace Materials, Processes, and Environmental Technology, (2001).

46. K. E. Lulay, K. Khan and D. Chaaya, The effect of cryogenic treatments on 7075 aluminum alloy. J. Mater. Eng. Perform, 11 (5), 479-480 (2002).

47. R. F. Barron, Effect of cryogenic treatment on lathe tool wear. in Proceedings of the 13th International Congress of Refrigeration, 1, 529-534 (1973).

48. R. F. Barron, Do treatments at temperature below $-120^{\circ} \mathrm{F}$ help increase the wear resistance of tool steels? Here are some research findings that they do. Heat Treating, 14-17, (1974).

49. R. F. Barron and C. R. Mulhern, Cryogenic treatment of AISI-T8 and C1045 steels. Adv. Cryog. Eng. Materi, 26, 171-178 (1980).

50.R. F. Barron, Cryogenic treatment of metals to improve wear resistance. Cryogenics, 22 (8), 409-313 (1982).

51. R. F. Barron, Cryogenic treatment of tool steels. in Proceedings of Conference Manufacturing Strategies, 6, 535-548 (1996).

52. A. Molinari, M. Pellizzari, S. Gialanella, G. Straffelini and K. H. Stiasny, Effect of deep cryogenic treatment on the properties of tool 
steel. in Proceedings of Conference on Advances Materials Processes Technologies, 1461-1469 (1999).

53.E. Gordo, F. Velasco, N. Candela, J. M. Torralba, M. Pellizzari and A. Molinari, Cryogenic treatment on HSS base composites reinforced with $\mathrm{Nb}$ and $\mathrm{Ta}$ carbides. in Proceedings of EUROPM'99 Conference, 75-82, (1999).

54.D. Yun, L. Xiaoping and X. Hongshen, Deep cryogenic treatment of high-speed steel and its mechanism. Heat Treat. Met, 3, 55-59 (1998).

55. K. P. Kollmer, Applications and Developments in the Cryogenic Processing of Materials. The Technology Interface, Electronic Journal for Engineering Technology, 3 (1) (1999).

56. A. Bensely, D. Senthilkumar, D. Mohan Lal, G. Nagarajan, and A. Rajadurai, Effect of cryogenic treatment on tensile behavior of case carburized steel-815M17. Mater. Charact, 58, 485-491 (2007).

57.G. Belisario, F. Caproni and E. Marchetti, Influence of low temperature treatment on fatigue life of strain hardened steel specimen. in Proceedings of the Eleventh International Cryogenic Engineering Conference - ICEC 11, D, 791-794 (1986).

58. M. Pellizzari, A. Molinari, S. Gialanella and G. Straffelini, Effetto del trattamento criogenico sulle proprietà microstrutturali dell'acciaio AISI H13. La Metallurgia Italiana, 1, 21-27 (2001).

59.F. Meng, K. Tagashira, R. Azuma and H. Sohma, Role of etacarbide precipitations in the wear resistance improvements of Fe-12Cr-Mo-V-1. 4C tool steel by cryogenic treatment. ISIJ Int, 34 (2), 205-210 (1994).

60. A. Molinari, M. Pellizzari, S. Gialanella, G. Straffelini and K. H. Stiasny, Effect of deep cryogenic treatment on the mechanical properties of tool steels. J. Mater. Process. Technol, 118, 350-355 (2001).

61. A. Kaushal, S. K. Saluja, and R. S. S. Rawat, Effect of Cryogenic Treatment on Tool Steel (AISI D2). International Journal of Research in Engineering and Technology, 4 (1), 80-383 (2015).

62.D. Jandova, P. Suchmann, and J. Niznanska, Microstructure of Tool Steel X37CrMoV5 after Cryogenic Treatment and its Effect on Wear Resistance. Key Engineering Materials, 647, 23-37 (2015).

63.S. Ather, and S. A. Sonawane, Wear resistance Enhancement of AISI D3 Tool steel by Cryogenic Treatment. International Journal of Current Engineering and Technology, 5 (3), 1777-1780 (2015).

64.F. Meng, K. Tagashira and H. Sohma, Wear resistance and microstructure of cryogenic treated $\mathrm{Fe}-1.4 \mathrm{Cr}-1 \mathrm{C}$ bearing steel. Scripta Metall. Mater, 31 (7), 865-868 (1994).

65.M. Preciado, P. M. Bravo and J. M. Alegre, Effect of low temperature tempering prior cryogenic treatment on carburized steels. J. Mater. Process. Technol, 176, 41-44 (2006).

66. A. Y. L. Yong, K. H. W. Seah and M. Rahman, Performance evaluation of cryogenically treated tungsten carbide tools in turning. Int. J. Mach. Tool. Manu, 46, 2051-2056 (2006).

67.H. S. Yang, J. Wang, B. L. Shen, H. H. Liu, S. J. Gao and S. J. Huang, Effect of cryogenic treatment on the matrix structure and abrasion resistance of white cast iron subjected to destabilization treatment. Wear, 261, 1150-1154 (2006).

68. H. H. Liu, J. Wang, B. L. Shen, H. S. Yang, S. J. Gao SJ and S. J. Huang, Effects of deep cryogenic treatment on property of 3 Cr13Mo1V1. 5 high chromium cast iron. Mater. Des, 28, 10591064 (2007). 